\title{
The Evaluation of the Surgical and Functional Reseults of the Tumor Resection Prothesis in Proximal Femur Malignant Bone Tumors
}

\section{Proksimal Femur Malign Kemik Tümörlerinde Tümör Rezeksiyon Protezi Cerrahi ve Fonksiyonel Sonuçlarının Değerlendirilmesi}

\author{
Selçuk Yılmaz, İsmail Burak Atalay, Recep Öztürk, Bedii Şafak Güngör ${ }^{1}$ \\ Ankara Onkoloji Hastanesi, Ortopedi ve Travmatoloji Kliniği, Ankara
}

Dergiye Ulaşma Tarihi:04.12.2018 Dergiye Kabul Tarihi:19.03.2019 Doi: 10.5505/aot.2019.62134

\section{ÖZET}

GİRIŞ ve AMAÇ: Günümüzde, etkili kemoterapötik ilaçlar ve teknolojik gelişmeler malign kemik tümörlerinin tedavisinde, hastaların çoğunda amputasyon yerine ekstremite koruyucu cerrahi girişimleri mümkün kılmıştır. YÖNTEM ve GEREÇLER: Ankara Onkoloji Hastanesi Ortopedi ve Travmatoloji Kliniğinde Ocak 2003 ile Haziran 2016 tarihleri arasında femur proksimal primer ve metastatik kemik tümörlerinde proksimal femur tümör rezeksiyon protezi yapılan 240 hasta çalışmaya alınmıştır.

BULGULAR: Çalışmaya alınan 240 hastanın 119'u kadın (\%49.6) 121' i erkek (\%50.4) hastalardan oluşmaktaydı. Hastaların cerrahi zamanındaki yaş ortalaması 53.6 (14-82) yıldı, etkilenen ekstremite 122 'sinin ( $\% 50,6)$ sağ, 118'i $(\% 49,4)$ sol ekstremitesiydi. Hastalarımızın ortalama takip süresi 29.3 ( 1-155) aydı. Hastalarımızın fonksiyonel değerlendirmesi Kas-İskelet Sistemi Tümörleri Derneği (MSTS: Musculoskeletal Tumour Society) skorlama sistemine göre yapıldı. Genel olarak hastalarımız ele alındı̆̆ında tüm serilerdeki ortalama MSTS skoru \% 71,3'tü. Primer kemik tümörü grubunun ortalama MSTS skoru \%80,4, metastatik kemik tümörü grubunun MSTS skoru \% 67,4' tür.

Femur proksimal rezeksiyon artroplatisinin en önemli komplikasyonu protez dislokasyonudur ve sonuçlarımız literatürle benzerdir. Başarılı endoprostetik reskonstrüksiyon için iyi bir yumuşak doku örtümü, kapsül onarımı ve efektif abdüktör mekanizma onarımı şarttır

TARTIŞMA ve SONUÇ: Endoprotez rekonstrüksiyonları erken dönemde çok iyi fonksiyonel sonuç sağlama avantajlarına sahipken, orta ve uzun dönemde özellikle genç ve aktif hastalarda mekanik komplikasyonlara yol açmaktadır. Ekstremite kurtarıcı cerrahi "önce hayat, sonra konforlu hayat" felsefesinden sapma göstermeden uygulandı̆̆ 1 taktirde yüzgüldürücü sonuçlar vermeye devam edecektir.

Anahtar Kelimeler: rezeksiyon protezi, rezeksiyon artroplastisi, proksimal femur

\begin{abstract}
INTRODUCTION: Effective chemotherapeutics and technologic developement made limb salvage procedures available instead of amputation in malignant bone tumour therapy.

METHODS: 240 patients treated with the diagnosis of malign bone tumor of proximal femur with proximal femoral resection endoprothesis in Ankara Oncology Hospital between January 2003 and June 2016 are included in this retrospective study.

RESULTS: Among these 240 patients 121(50,4\%) were male and 119(49,6\%) were female. The mean age in the diagnosis was 53,6(14-82), the affected extremity was left in \%50,6(118) and right in \%49,4 (122). The mean follow up period was 29,3 months(1-155months). Fonctional evaluation was made by MSTS (Musculoskeletal Tumour Society) scoring system. The overall average MSTS score of patients discussed is $\% 71,3$. The avarage MSTS score of the primay malign bone tumors is \%80,4, metastasis of the bone tumors is \%67,4.

The most important complications of proximal femoral resection arthroplasty is dislocation of the prothesis, and our results are similar to the literature. For a succesful endoprosthetic surgery must have a good soft tissue reconstruction, good capsule repair and effective abductor mechanism repair.

DISCUSSION AND CONCLUSION: Although reconstructions by endoprostheses have early stage adventages of excellent functional results, they cause mechanical complications especially in young and active patients in mid and late stages. Good results may be expected from limb salvage surgery if life precedes comfort in decision making.

Keywords: resection prosthesis, resection arthroplasty, proximal femur.
\end{abstract}




\section{GíRiş}

Primer ve metastatik malign kemik tümörlerinde en uygun cerrahi yaklaşımın seçiminde hastanın yaşı, tümörün lokalizasyonu ve invazyonu etkili olmaktadır. İskelet rekonstrüksiyon seçenekleri arasında; endoprotezler, osteoartiküler veya bulk allogreftler, allogreft-protez sistemleri, vaskülarize kemik greftleri, artrodez, uzayabilen protezler, rotasyonplasti ve ilizarovla kemik transportu sayllabilir $(1,2)$. Bu yöntemleri uygularken iki kilit noktaya dikkat etmek gerekir; sağ kalım oranları amputasyona göre daha kötü olmamalı ve uzuva yeterli işlev kazandırılmalıdır. Modüler sistem endoprotezlerin 1980'li yılların ortalarında geliştirilmesi ile birlikte operasyon öncesi bekleme süreleri kısald, rezeksiyon miktarlarına peroperatif karar verilebildi $(3,4)$. Erken mobilizasyon, yük verme, stabilite, operasyon ve hastane yatış sürelerinin süresinin k1sa olması, adjuvan kemoterapiye daha erken başlanması olanağı sağladı.

Primer kemik tümörlerinin tedavisindeki gelişmeler ile sağkalım sürelerinin uzaması, yaş ortalaması genç, aktif yaşam beklentisi olan bu hastalar için daha sağlam ve dayanıklı protez ihtiyacını doğurdu. $\mathrm{Bu}$ beklentiler 1şı̆̆ında endoprotezlerin devamlılığ1 ve dayanıklılığ ihtiyacının azaltılmasında önemli yer tuttu (4).

$\mathrm{Bu}$ çalışma ile femur proksimal primer kemik tümörleri ve metastatik kemik hastalığ1 tanısı ile kliniğimizde modüler endoprostetik rekonstrüksiyon uygulanan hastaların klinik özellikleri, cerrahi komplikasyonları ve fonksiyonel sonuçları sunmak ve bu sonuçların yapılan önceki çalışmalarla kıyaslanması amaçland.

\section{GEREÇ VE YÖNTEM}

2003-2016 y1lları arasında femur proksimal primer ve metastatik kemik tümörü nedeniyle proksimal femur rezeksiyon protezi uygulanan 121 erkek, 119 kadın toplam 240 hasta çalışmaya dahil edildi. Ortalama yaşları 53,6 idi. Hasta kayitları mevcut dosyalar ve film arşivleri taranarak retrospektif olarak analiz edildi.

Kliniğe başvuran tüm hastalardan detaylı hikaye alınarak fizik muayene yapıldı, kitle boyutları, kıvamları, yerleşimleri, ağn, hareket kısitlılığ değerlendirildi. Tüm hastalara direkt radyografi, akciğer grafisi, tümör bölgesine yönelik MRG ve/veya BT, radyolojik evreleme amacı ile akciğer ve batın BT ve/veya PET, tüm vücut kemik sintigrafisi tetkikleri yapıldı. Biyopsi ve definitif operasyonlar açısından MRG ve BT tetkikleri incelenerek preoperatif planlama yapıldı. Radyolojik değerlendirme sonrası kapalı trokar biyopsi ya da insizyonel biyopsi uygulanarak patolojik tanı kondu. Trbbi onkoloji ve radyasyon onkolojisi kontrolünde hastalara patolojik tanılarına göre neoadjuvan ve adjuvan tedaviler uyguland.

Tüm hastalara genel anestezi altında cerrahi yapıldı. Sağlam kalça üzerinde yan yatan hastanın kalçasına posterolateral yaklaşım kullanıldı.

Opere edilen hastalar düzenli olarak kontrole çağrildı. Kontrol muayeneleri klinik muayene ve patolojinin cinsine göre tümör markerları, akciğer grafisi ve BT'si, bölgesel radyografi, BT, MRG ve sintigrafik yöntemler yardımı ile yapıldı.

Fonksiyonel

sonuçların değerlendirilmesinde MSTS (musculo skeletal tumor society) skorlama sistemi kullanıldı (5).

Elde edilen tüm veriler Excel 2000 ve SPSS 13.0 programında kaydedildi. İstatistikler için SPSS programından yararlanıldı. Karşılaştırmalar için ki kareanalizi yapıldı. İstatistiksel anlamlılık için sinır değer $\mathrm{p}<0.05$ olarak kabul edildi.

\section{BULGULAR}

240 hastanın 121'ü $(\% 50,4)$ erkek, 119'u $(\% 49,6)$ kadındı. En genç olgumuz 14 yaşında en yaşlı olgumuz ise 82 yaşındaydı, ortalama yaş 53,6 yı idi. Hastaların klinik ve demografik özellikleri Tablo 1'de özetlendi.

Hastalarımızın primer kemik tümörü olanları ortalama takip süresi 70,3 ay(8-155), metastatik kemik tümörü olanları ortalama takip süresi 12,1 aydır.(1-68). Hastalarımızın takipleri sirasinda 71 primer kemik tümörü olan hastaların 31'i öldü, 169 metastatik kemik tümörü olan hastaların 138'i öldü.

Hastalarımızın ortalama postoperatif MSTS skoru \%71.3 (16-100). Tüm seride: Mükemmel 49 (\%20), İyi 86 (\%34), Orta78 (\%31), Kötü 37 (\%15) sonuç elde edildi. 
Cinsiyeti erkek olan hastaların MSTS skoru\%73,1 (24-100), kadın olanların MSTS skoru\%69,4 (16-90) olarak bulundu. İki grup arasında anlamlı fark yoktur. $(\mathrm{p}>0,05)$.

Primer kemik tümörlü grupta MSTS skoru \%80,4 (42-100) iken, metastatik tümörlü grupta \%67,4 (16-90) olarak bulundu. Primer kemik tümörlü grupta MSTS skoru istatistiksel olarak anlamlı derecede yüksek bulundu $(\mathrm{p}<0,05)$.

Patolojik kırı̆g 1 olan hastaların MSTS skoru\%60,1(16-80), patolojik kırı̆̆ olmayan hastaların MSTS skoru \%85,2(35-100). Patolojik kırık olmayan grupta MSTS skoru istatistiksel olarak anlamlı derecede yüksek bulundu.

Araştırmaya alınan 240 hastanın \% 31.25 'inde (75 hasta) takip süreleri boyunca herhangi bir zamanda komplikasyon gelişti. Komplikasyon gelişme zamanı ortalama 13.3 ay (0-240) olarak bulundu.

Lokal nüks sebebiyle 4 hastaya ampütasyon yapıldı. $\mathrm{Bu}$ hastaların 2'si osteosarkom, 1'i kondrosarkom, 1'i pleomorfik sarkomdu. Amputasyon uygulanan hastalardan biri adjuvan kemoterapi tedavisini reddetti ve takip sırasında akciğer metastazları nedeni ile öldü.

Endoprotez başarısızlığına neden olarak revizyonla sonuçlanan en önemli nedenlerden biri instabilite ve dislokasyon oldu. Dislokasyonla sonuçlanan proksimal femur endoprostetik rekonstrüksiyonlarından (bipolar hemiartoplasti) 6 hastaya revizyon yapıldı. Kalan diğer hastalar ise genel anestezi altında kapalı (26 hasta) veya açık ( 8 hasta) redüksiyon ile başarılı olarak tedavi edildi. İnstabilite hastaların ilk 3 aylık takiplerinde gelişti. Ortalama geçen süre 8,6 (1-43) aydı.

Yüzeyel cilt enfeksiyonu gelişen 14 hastanın tamamı yara pansumanı ve antibiyoterapi ile iyileşti. 2 hastada $(\% 0,83)$ aseptik gevşeme gözlendi. $\mathrm{Bu}$ hastalara implant çıkarımı ve revizyon operasyonu yapıld1. Protez enfeksiyonu 4 hastada gelişti. Ortalama 12.5 (1-33) ayda gelişti. Hastalar debridman, y1kama ve antibiyoterapi sonras1 iyileşti. İntraoperatif alınan kültürlerde en sık etken Staphilococcus Aureus'tur. Protez enfeksiyonu-yaş ve protez enfeksiyonurezeksiyon miktarı arasinda yapılan korelasyon analizi sonuçları istatistiksel olarak anlamlı değildi. $(\mathrm{p}>0,05)$
Takipler sirasinda 1 hastada periprostetik kırık gelişti. Bu hastada femoral stem distalinde nüksü olması sebebiyle total femur protezine geçildi. 10 hastada siyatik sinir arazı gelişti. 8 tanesi erken postoperatif dönemde görüldü, 2 tanesi luksasyon sonras1 görüldü. 3 hastanın sinir arazı takipler sırasında düzeldi.

Tablo 1: Hastaların klinik ve demografik özellikleri

\begin{tabular}{|c|c|}
\hline Yaș (y1l) (ortalama, min-max) & $53.6(14-82)$ \\
\hline \multicolumn{2}{|l|}{ Cinsiyet $\mathrm{n},(\%)$} \\
\hline - Erkek & $121(550.4)$ \\
\hline - Kadin & $119(\% 49.6)$ \\
\hline Takip Süresi (ay) & $70.3(8-155)$ \\
\hline Primer $\mathrm{n},(\%)$ & $71(\% 78.6)$ \\
\hline Metastaz n, (\%) & $169(\% 21.4)$ \\
\hline Patolojik Kirık & $133(\% 55.4)$ \\
\hline \multicolumn{2}{|l|}{ Lokalizasyon $\mathrm{n},(\%)$} \\
\hline - $\quad$ Femur başı -boyun & $123(\% 51)$ \\
\hline - $\quad$ Femur intertrokanterik & $41(\% 17)$ \\
\hline - $\quad$ Subtrokanterik & $65(\% 27)$ \\
\hline - $\quad$ Diafiz & $11(\% 5)$ \\
\hline \multicolumn{2}{|l|}{ Histopatolojik Tanı } \\
\hline - $\quad$ Kondrosarkom & $22(\% 9.1)$ \\
\hline - Osteosarkom & $16(\% 6.6)$ \\
\hline - $\quad$ Ewing sarkom & $10(\% 4.1)$ \\
\hline - $\quad$ Multpl myelom & $8(\% 3.2)$ \\
\hline - $\quad$ Malign mezenkimal tümör & $7(\% 2.9)$ \\
\hline - $\quad$ Diğer primer & $8(\% 3.2)$ \\
\hline tümörler & $59(\% 24.5)$ \\
\hline - $\quad$ Meme CA & $25(\% 10.4)$ \\
\hline - $\quad$ Akciğer CA & $21(\% 8.7)$ \\
\hline - $\quad$ Prostat CA & $13(\% 5.4)$ \\
\hline Böbrek CA & $51(\% 21.2)$ \\
\hline - $\quad$ Diğer Metastazlar & \\
\hline
\end{tabular}

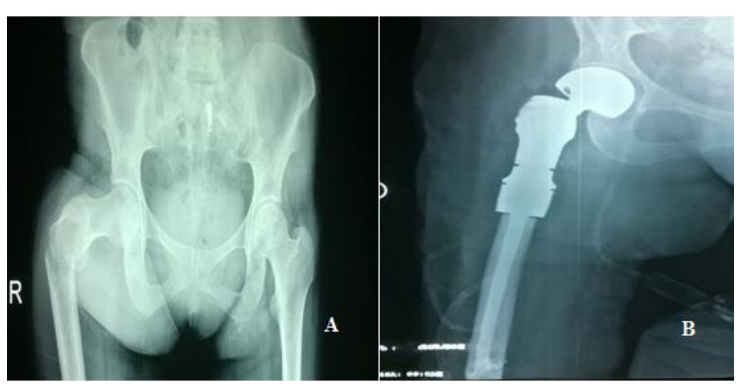

Resim 1. 60 yaş, kadın,meme CA, sağ femur subtrokanterik patolojik kırı̆̆ A) Preoperatif direkt grafi B) Postoperatif direkt grafi 


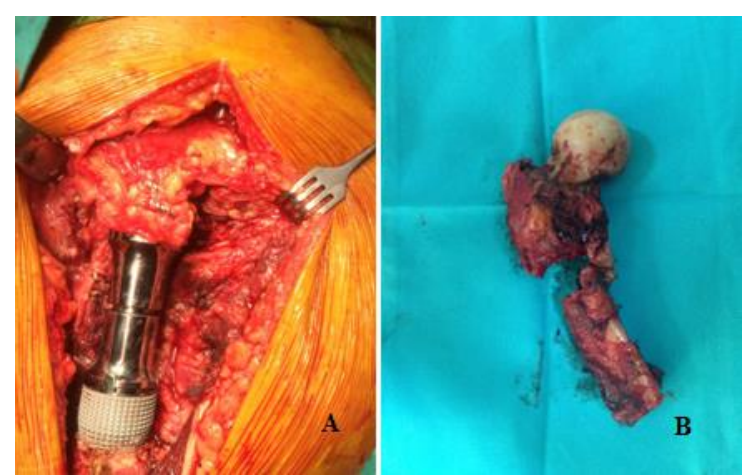

Resim 2. 50y, erkek, mesane CA, sağ femur intertrokanterik patolojik kırığı A) İntraoperatif abdüktör mekanizmanın onarılmış hali B) Patolojik kırığın makroskopik görünümü

\section{TARTIŞMA}

Hastaların yaş ortalamalarını Natarjan ve arkadaşları 9 hastadan oluşan serilerinde 47.7(35-60) (6), Menendez ve arkadaşları 96 hastadan oluşan serilerinde 59(14-86) (7), Hattori ve arkadaşlarının 22 hastadan oluşan serisinde $61.8 \quad(37-78) \quad(8)$, İlbeyli ve arkadaşları 27 hastadan oluşan serilerinde 54.9(16-75)(9), Chan ve arkadaşları 38 hastadan serilerinde yaş ortalamasını 54 olarak belirtmişlerdir (10), Pannekamp ve arkadaşların 20 hastadan oluşan serilerinde yaş ortalaması 62(18-82) olarak belirtmiştir (11).

Sanjay ve arkdaşları 17 erkek ve 16 kadından oluşan 33 hastalık serilerinde yaş ortalamasını 27 (16-69) olarak belirtmişleridir (12). Wang ve arkadaşlarının 62 hastadan oluşan serilerinde (29 erkek-33 kadın) yaş ortalamas1 35(14-73) olarak belirtmişlerdir (13). Chandrasekar ve arkadaşlarının 100 hastadan oluşan serilerinde (45 erkek-55 kadın) yaş ortalamsını 60.2 olarak belirtmişlerdir (14).

Bizim serimizdeki 240 hastanın yaş ortalamas1 53.6 (14-82) olup diğer çalışmalardaki değerler ile uyumludur. Literatürde metastatik tümörlerin yaş dağ 11 เmı 23 yaş ile 88 yaş arasında değişmektedir. Metastatik tümörlü hastaların yaş ortalaması primer malign kemik tümörlü hastaların yaş ortalamasından oldukça yüksektir. Bizim çalışmamızda metastatik kemik tümörü olan hastaların yaş ortalaması 55,3, primer kemik tümörü olan hastaların yaş ortalaması 49,5 olup istatiksel olarak anlamlı bulunmuştur.
Proksimal femur yerleşimli tümör nedeni ile proksimal femur rezeksiyon protezi uygulanan hastalardaki takip sürelerini Chan ve arkadaşları ortalama 14.7 ay (2.5-70 ay)(10), Pannekamp ve arkadaşları ortalama 20.3 ay (4-51 ay) (11), Menendez ve arkadaşları ortalama 18.1 ay (1-129 ay) (7), Camnasio ve arkadaşları ortalama 26 ay olarak belirtmişlerdir (15), Sanjay ve arkadaşları 33 hastadan oluşan serilerinde ortalama takip süresi 50 ay (14-79) olarak belirtmişlerdir (12).

Wang ve arkadaşlarının 62 hastadan oluşan serilerinde yaşayan 36 hastanın ortalama takip süresi 64 ay (28-221) olarak belirtmişleridir (13). Robert ve arkadaşlarının 63 hastadan oluşan serilerinde yaşayan 18 hastanın ortalama takip süresi 30 aydır (10-48) (16), Chandrasekar ve arkadaşlarının 100 hastadan oluşan serilerinde ortalama takip süresini 15.4 ay olarak belirtmişlerdir (14), Potter ve arkadaşlarının 61 hastadan oluşan (22 primer, 39 metastatik) serilerinde yaşayan 30 hastanın ortalama takip süresi 55.4 ay olarak belirtilmiştir (17).

Bizim serimizde ise ortalama takip süresi 70.3 aydır (8-155 ay). Bizim serimizde takip süresinin daha uzun olmasının sebebi daha yüksek sayıda hastanın çalışmaya dahil edilmesidir.

Proksimal femur yerleşimli tümör nedeni ile proksimal femur rezeksiyon protezi uygulanan hastalardaki ortalama MSTS skoru İlyas ve arkadaşları çalışmalarında \%63(\%4086) olarak belirtmiştir (18), Potter ve arkadaşları $\quad \% 71.7 \quad(\% 43.3-93.3) \quad$ olarak belirtmiştir (17), Menendez ve arkadaşları \%73(\%50-83) olarak belirtmiştir (7), Thambapillary ve arkadaşlarının 668 hastadan oluşan derlemelerinde ortalama MSTS skoru \%70.8 olarak belirtmiştir (19), Wang ve arkadaşlarının 62 hastadan oluşan serilerinde ortalama MSTS skoru \%77.6 olarak belirtilmiştir (13), Hattori ve arkadaşları \%62.3 (\%44-80) (8) olarak belirtmiştir. Pannekamp ve arkadaşları ortalama MSTS skoru \%73 (\%50-83) olarak belirtmiş, hastaların $\% 20$ 'sinde mükemmel, \%26.7'sinde iyi, $\% 40$ 'ında yetersiz, \%13.3'ünde kötü sonuç elde etmiştir (11). İlbeyli ve arkadaşları ise ortalama MSTS skoru \%68.6 bulmuş ve hastaların \%55.5'inde iyi, \%37.3'ünde orta, \%7.4'ünde kötü fonksiyonel sonuç elde etmiştir (9), Khee ve arkadaşlarının 19 
hastadan oluşan serilerinde ortalama MSTS skoru \% 78.3 olarak belirtilmiştir (20).

Donati ve arkadaşlarının 25 hastada oluşan serilerinde 7 hastada mükemmel sonuç, 10 hastada iyi sonuç, 7 hastada yetersiz sonuç ve 1 hastada kötü sonuç elde 80 edilmiştir. (21) Camnasio ve arkadaşlarının 102 hastadan oluşan serilerinde 20 hastada mükemmel sonuç (\%19.6),65 hastada iyi sonuç (\%54.2), 17 hastada yetersiz sonuç (\%26.2) elde edilmiştir (14), Sanjay ve arkdaşları 33 hastadan oluşan serilerinde 16 hastada mükemmel sonuç, 4 hastada iyi sonuç, 4 hastada yetersiz sonuç, 9 hastada kötü sonuç elde edilmiştir (12).

Park ve arkadaşlarının masif endoprotez uyguladıkları kemik tümörü olan 31 hastanın 11'i proksimal femur rezeksiyon artroplastisiydi. $\mathrm{Bu} 11$ hastanın ortalama MSTS skoru \%72.4 (57-83) olarak belirtilmiştir (20).

Bizim serimizde proksimal femur yerleşimli tümör nedeni ile femur proksimal tümör rezeksiyon protezi yapılan 240 hastanın ortalama MSTS skoru \%71,3'tür (\%16-100). Hastaların \%20'sinde mükemmel, \%34'ünde iyi, \%31'inde orta, \%15'inde kötü sonuç elde edilmiştir.

Serimizdeki primer ve metastatik tümörlü hastalardaki postoperatif ortalama MSTS skorları literatürle paralellik göstermekte olup primer tümörlü grupta metastatik tümörlü gruba göre istatiksel olarak anlamlı düzeyde yüksek bulunmuştur. Primer kemik tümörü olan 71 hastanın ortalama MSTS skoru \%80,4 olup, metastatik kemik tümörü olan 169 hastanın ortalama MSTS skoru \%67,4'tür. Yine çalışmamıza paralel olarak Potter ve arkadaşları primer kemik tümörleri için MSTS skoru \%80,2, metastatik kemik tümörleri için MSTS skoru \%66.8 olarak bulmuştur (17), Yalnız ve arkadaşları ortalama MSTS skoru primer tümörlü grupta metastatik tümörlü gruba göre anlamlı düzeyde yüksek bulunmuştur (22).

Proksimal femur yerleşimli tümör nedeniyle modüler tümör rezeksiyon protezi uygulanan hastalardaki komplikasyon oranı Hattori ve arkadaşlarının serilerinde \%10.5 olup, gelişen komplikasyonların hepsi protez dislokasyonuydu (8). Pannekamp ve arkadaşlarının serilerinde $\% 22.7$ oranında komplikasyon görülmüş olup, gelişen komplikasyonlar \%13.6 oranında protez enfeksiyonu, \%9.1 oranında protez dislokasyonudur (11). İlyas ve arkadaşlarının serilerinde ise $\% 53$ oranında komplikasyon gelişmiştir. Gelişen komplikasyonlar sırasıyla $\% 20$ oranında protez dislokasyonu, \%14 oranında protez enfeksiyonu, $\% 7$ oranında aseptik gevşeme ve $\% 7$ oranında lokal nükstür (18). Chan ve arkadaşlarının serisinde hastaların takibinde $\% 18$ oranında komplikasyon gelişmiş olup , \%10 oranında protez dislokasyonu, $\% 6$ oranında protez enfeksiyonu, $\% 3$ oranında siyatik sinir arazı raporlamışlardır (10).

Robert ve arkadaşlarının 63 hastadan oluşan serilerinde 22 hastada (\%35) protez dislokasyonu görülmüştür. $\mathrm{Bu}$ hastaların 9 tanesine kapalı redüksiyon uygulanmış, 11 hastaya açık redüksiyon uygulanmıştır. Diğer 2 hastada ise tekrarlayan dislokasyonlar nedeniyle revizyon cerrahisi uygulanmıştır. 4 hastada enfeksiyon gelişmiştir. Bu hastalardan 2 hastaya tek basamaklı revizyon cerrahisi, 1 hastaya debridman ve antibiyoterapi, 1 hastaya sadece antibiyoterapi tedavisi verilmiştir (16). Chandrasekar ve arkadaşlarının 100 hastadan oluşan serilerinde 3 hastada protez dislokasyonu görülmüştür. 4 hastada ise derin enfeksiyon görülmüştür. 1 hastada enfeksiyon nedeniyle kalça dezartikülasyonu yapılmıştır (14).

Khee ve arkadaşlarının 19 hastadan oluşan serilerinde 3 hastada erken enfeksiyon gelişmiştir, intravenöz antibiyoterapi ile tedavi edilmiştir. 3 hastada geç enfeksiyon gelişmiş olup bu hastların ikisi intravenöz antibiyoterapi ile tedavi edilmiştir, bir hastaya debridman yapılmıştır. 2 hastada protez dislokasyonu gelişmiştir (20).

Özetle proksimal femur replasmanları sonras1 literatürde en s1k görülen komplikasyon sirasiyla protez dislokasyonu ve protez enfeksiyonudur. Bizim serimizde \%30,8 oranında komplikasyon gelişmiş olup en sik görülen komplikasyon \%51 oranında protez dislokasyonudur. Sonuçlarımız literatürle uyum göstermekte olup proksimal femoral rezeksiyon sonrası uygulanan modüler tümör protezlerinde dislokasyon oranının geleneksel kalça artroplastisi için bildirilen rakamların üzerinde olmasını geniş tümör rezeksiyonu sonras1 abdüktör kas gücündeki kayba bağl1 olduğunu düşünmekteyiz. 


\section{SONUÇ}

Femur proksimal rezeksiyon protezi önemli bir cerrahi uygulama olması ve yüksek komplikasyon riskine rağmen, iyi seçilmiş olgularda ekstremite fonksiyonlarının tatminkar bir şekilde korunabildiği bir prosedürdür. Ancak bu prosedür artroplasti ve kas iskelet sistemi tümörleri konusunda yeterli bilgi ve deneyime sahip merkezlerde uygulanmalidir.

Femur proksimal rezeksiyon artroplatisinin en önemli komplikasyonu protez dislokasyonudur. Başarılı endoprostetik rekonstrüksiyon için iyi bir yumuşak doku örtümü, kapsül onarımı ve efektif abdüktör mekanizma onarımı şarttır.

\section{REFERANSLAR}

1. Gebhardt MC, Flugstad DJ, Springfield DS, Mankin HJ. The use of bone allografts for limb salvage in high-grade extremity osteosarkoma. Clin Orthop 1991; 270: 181-96.

2. Zehr RJ, Enneking WF, Scorborough MT. Allografts-prothesis composite versus megaprothesis in proksimal femoral rekonstruction. Clin Orthop 1996; 322: 207-23.

3. Henshaw, R.M. and M.M. Malawer, Advances in modular endoprosthetic reconstruction of osseous defects. Current Opinion in Orthopaedics, 2003. 14(6): 429-37.

4. Ahlmann, E.R., Survivorship and clinical outcome of modular endoprosthetic reconstruction for neoplastic disease of the lower limb. J Bone Joint Surg Br, 2006.88(6):790-5

5. Enneking WF, Dunham W, Gebhardt MC, Malawer M, Pritchard DJ. A system for the functional evaluation of the reconstructive procedures after surgical treatment of tumors of the musculoskeletal system. Clin Orthop 1993; 286: 241-261.

6. Natarjan MV, Mohanlal P, Bose JC. The role of limg salvage and custom mega prothesis in multiple myeloma. Acta Orthop Belg, 2007 Aug;73(4):462-7

7. Menendez LR, Ahlmann ER, Kermani C, Gotha $\mathrm{H}$.,Endoprosthetic reconstruction for neoplasms of the proximal femur. Clin Orthop Relat Res. 2006Sep;450:46-51

8. Hattori H, Mibe J, Yamamoti K. Modular Megaprothesis in Metastatic Bone Disease of the Femur. Orthopedics. 2011 Dec 6;34(12)
9. İlbeyli H, Alt ekstremite primer malign ve metastatik kemik tümörlerinde rezeksiyon artroplastisi sonuçları, uzmanlık tezi, Adana, 2005

10. Chan D, Carter SR, Grimer RJ, Sneath RS. Endoprosthetic replacement for bony metastases. Ann R Coll Surg Engl. 1992

11. Pennekamp PH, Wirtz DC, Dürr HR. Proximal and total femur replacement. Oper Orthop Traumatol. 2012 Jul;24(3):215-26

12. B.K.S. Sanjay, P.G. Moreau Limb salvage surgery in bone tumour with modular endoprosthesis International Orthopaedics (SICOT) (1999) 23:4146

13. Wang J, Yin J, Zou C, Xie X, Huang G, Li H, Shen J, Han S. Surgical treatment of proximal femoral malignant tumors Zhongguo Xiu Fu Chong Jian Wai Ke Za Zhi. 2010 Jul;24(7):881-4.

14. Chandrasekar CR, Grimer RJ, Carter SR, Modular endoprosthetic replacement for metastatic tumours of the proximal femur, J Orthop Surg Res. 2008 Nov 4;3:50

15. F. Camnasio,C. Scotti,G. M. Perett, F. Fontana,G. Fraschini Prosthetic joint replacement for long bone metastases: analysis of 154 cases Arch Orthop Trauma Surg (2008) 128:787-93

16. Robert U. Ashford, Sammy A. Hanna, Derek H. Park Proximal femoral replacements for metastatic bone disease: financial implications for sarcoma units International Orthopaedics (SICOT) (2010) 34:709-713

17. Potter, B.K., et al., Endoprosthetic proximal femur replacement: metastatic versus primary tumors. Surgical oncology, 2009. 18(4): 343-49.

18. Ilyas I, Pant R, Kurar A, Moreau PG, Younge DA. Modular mega prothesis for proximal femoral tumors. Int Orthop. 2002;26(3):170-3

19. Thambapillary $\mathrm{S}$, Dimitriou $\mathrm{R}$, Makridis $\mathrm{KG}$, Fragkakis EM, Bobak P, Giannoudis PV. Implant longevity, complications and functional outcome following proximal femoral arthroplasty for musculoskeletal tumors: a systematic review. J Arthroplasty 2013 Sep;28(8):1381-5

20. P Khee, M Hong, Functional Outcome Study of Mega-Endoprosthetic Reconstruction in Limbs With Bone Tumour Surgery, Annals Academy of Medicine, March 2009, Vol. 38 No. 3, 192-6

21. D. Donati, M. Zavatta, E. Gozzi, S. Giacomini, L. Campanacci, M. Mercuri Vol. 83-B, No. 8, November 2001 Modular prosthetic replacement of the proximal femur after resection of a bone tumour

22. Yalnız E, Çiftdemir M, Memişoğlu S. Functional results of patients treated with modular prosthetic replacement for bone tumors of the extremities. Acta Orthop Traumatol Turc 2008;42(4):238-245 